\title{
Pemurnian Gliserol dari Hasil Samping Produksi Biodiesel Minyak Kelapa Sawit \\ (Purification of Glycerol from the By-Product of Palm Oil Biodiesel \\ Production)
}

\author{
Fahrizal Hazra $^{1 *}$, Irfan Septiawan ${ }^{2}$ \\ 1'Departemen Ilmu Tanah dan Sumberdaya Lahan, Fakultas Pertanian IPB \\ JI. Meranti Kampus IPB Dramaga, Bogor \\ ${ }^{2}$ Alumni Program Keahlian Analisis Kimia, Program Diploma IPB \\ "penulis untuk korespondensi: e-mail: fhazra2011@yahoo.com
}

Diterima/disetujui : 22 Maret 2014/ 9 April 2014

\begin{abstract}
The process of making biodiesel made of palm oil produced as a by-product of glycerol with low purity levels, liquids, viscous blackish brown with a very alkaline $\mathrm{pH}(\mathrm{pH}$ $>10$ ). Glycerol is often referred to as crude glycerol. The process of refining glycerol that is by adding phosphoric acid concentration range. The average value of the levels of glycerol from glycerol purification results on the phosphoric acid concentration of $2.5 \%$, $5 \%$ and $7.5 \%(\mathrm{~V} / \mathrm{V})$ i.e. $81.2205 \%, 83.4609 \%$ and $80.7595 \%$. Determination of the levels of glycerol results showed samples of glycerol rough after the addition of phosphoric acid with different concentrations of already existing standards. The result analysis of glycerol after purification by the addition of phosphoric acid at concentrations of $5 \%$ is most suitable for the process of improving the purity of glycerol.
\end{abstract}

Keywords: crude glycerol, purification, phosphate acid, glycerol content

\section{PENDAHULUAN}

Biodiesel atau disebut juga biosolar merupakan sumber bahan bakar alternatif sebagai pengganti solar (Prihandana et al 2006). Pada proses produksi biodiesel berbahan baku minyak kelapa sawit dihasilkan produk samping berupa gliserol dengan kadar kemurnian yang rendah, gliserol ini sering disebut dengan gliserol kasar atau crude gliserol. Produk yang dihasilkan sekitar $10-20 \%$ dari total volume produk. Hal ini karena gliserol merupakan produk hasil samping utama pada industri biodiesel (Darnoko dan Cheryan 2000). Indonesia berpeluang besar untuk mengembangkan penggunaan biodiesel dari minyak kelapa sawit (Suirta 2009). Pemerintah Indonesia menargetkan penggunaan biodiesel sebagai salah satu sumber energi alternatif sebesar 4.7 juta kiloliter pada tahun 2025. Seiring dengan meningkatnya produksi biodiesel, maka gliserol yang dihasilkan akan semakin melimpah.

Gliserol kasar yang dihasilkan belum dimanfaatkan oleh industri biodiesel saat ini, karena mengadung banyak zat-zat pengotor (Appleby 2005). Bahan dominan yang terkandung dalam gliserol hasil samping produksi biodiesel adalah sisa metanol yang tidak bereaksi, sabun dari hasil reaksi antara asam lemak bebas dengan katalis kalium hidroksida, katalis kalium hidroksida yang digunakan pada proses trans-esterifikasi, sehingga gliserol kasar bersifat basa (Kocsisová dan Cvengroš 2006, El-Diwani et al 2009). Menurut Knohte (2005), gliserol kasar dari hasil samping produksi biodiesel 
berupa cairan kental berwarna coklat kehitaman, memiliki kadar kemurnian sekitar $50 \%$, dan $\mathrm{pH}$ yang sangat basa $(\mathrm{pH}>10)$. Oleh sebab itu, untuk meningkatkan kemurnian gliserol berdasarkan Standar Nasional Indonesia (SNI) 06-1564-1995 perlu dilakukan proses pengolahan yang tepat agar menghilangkan zat-zat selain gliserol (Noureddini et al 1998). Tujuan dari penelitian ini adalah mempelajari pengaruh penambahan asam fosfat untuk meningkatkan kadar kemurnian gliserol.

\section{METODOLOGI}

\section{Bahan dan Alat}

Bahan-bahan yang digunakan ialah gliserol kasar (crude gliserol), gliserol hasil pemurnian, etanol $96 \%$, asam fosfat teknis $85 \%, \mathrm{KOH} 0.1 \mathrm{~N}, \mathrm{NalO}_{4}, \mathrm{H}_{2} \mathrm{SO}_{4} 0.2 \mathrm{~N}, \mathrm{NaOH}$ $0.05 \mathrm{~N}, \mathrm{NaOH} 0.5 \mathrm{~N}$, etilen glikol, indikator fenolftalein (PP), indikator bromotimol biru (BTB), serta akuades.

Alat-alat yang digunakan ialah gelas piala $50 \mathrm{~mL}$ dan $250 \mathrm{~mL}$, hot plate, pengaduk magnetik, penyaring vakum, corong Buchner, corong pisah, termometer, serta kertas saring Whatmann nomor 41 digunakan untuk proses pemurnian gliserol. Neraca analitik, sudip, oven, tanur, cawan porselein, desikator, densitometer Anton Parr DMA 450, pH meter Schott Handylab pH 11, viskometer Brookfield DV-III Ultra, labu takar 50 $\mathrm{mL}, 100 \mathrm{~mL}, 250 \mathrm{~mL}$ dan $1000 \mathrm{~mL}$, labu ukur $100 \mathrm{~mL}$, Erlenmeyer $100 \mathrm{~mL}$ dan $500 \mathrm{~mL}$, buret $50 \mathrm{~mL}$, pipet mohr $5 \mathrm{~mL}$ dan $10 \mathrm{~mL}$, serta botol semprot digunakan untuk analisis sifat fisikokimia gliserol kasar dan gliserol hasil pemurnian.

\section{Analisis Sifat Fisikokimia Gliserol Kasar}

Gliserol kasar yang telah dipisahkan dari biodiesel dianalisis sifat fisikokimianya untuk mengetahui karakteristik gliserol sebelum dimurnikan. Sifat fisikokimia yang dianalisis seperti kadar gliserol, bilangan asam, kadar air, kadar abu, densitas, viskositas, dan $\mathrm{pH}$.

\section{Proses Pemurnian Gliserol}

Gliserol kasar sebanyak $200 \mathrm{~mL}$ dimasukkan ke dalam gelas piala $250 \mathrm{~mL}$ dan dipanaskan diatas hot plate hingga mencapai suhu $65^{\circ} \mathrm{C}$ sambil diaduk menggunakan pengaduk magnetik. Setelah itu ditambahkan larutan asam fosfat dengan variasi konsentrasi yaitu $2.5 \%, 5 \%$, dan $7.5 \%$ (v/v) dan diaduk selama 30 menit. Campuran didinginkan dan didiamkan sampai terbentuk tiga lapisan. Lapisan berbentuk garam dipisahkan dengan kertas saring Whatmann nomor 41 menggunakan corong Buchner. Kemudian hasil penyaringan tersebut dipisahkan kembali menggunakan corong pisah. Lapisan bawah (gliserol) diambil dan disimpan. Proses pemurnian gliserol dari hasil samping produksi biodiesel minyak kelapa sawit dapat dilihat pada Gambar 1 . 


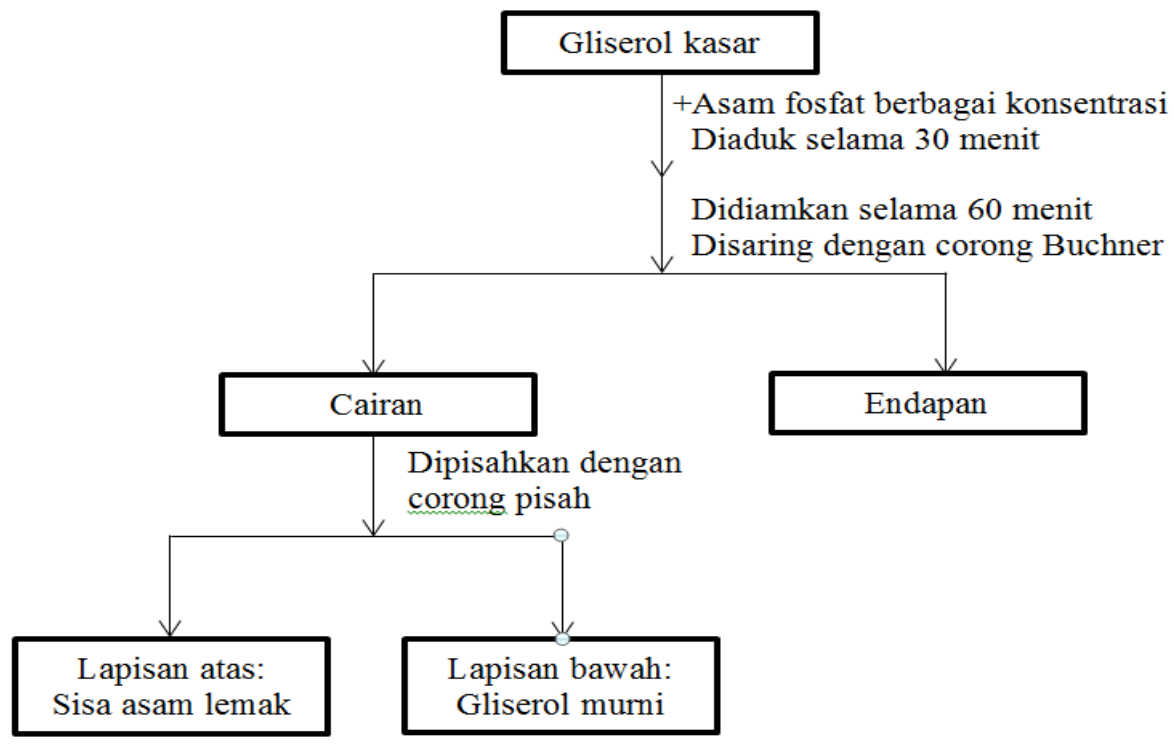

Gambar 1 Diagram alir proses pemurnian gliserol

\section{Analisis Sifat Fisikokimia Gliserol Hasil Pemurnian}

Gliserol hasil pemurnian dianalisis sifat fisikokimianya (kadar gliserol, bilangan asam, kadar air, kadar abu, densitas, viskositas, dan $\mathrm{pH}$ ) untuk membandingkan karakteristik gliserol sebelum dimurnikan (gliserol kasar). Analisis yang dilakukan sesuai dengan analisis fisikokimia pada gliserol kasar. Pengambilan data dilakukan sebanyak 3 kali ulangan.

\section{HASIL DAN PEMBAHASAN}

Hasil analisis perbandingan sifat fisikokimia dari gliserol kasar dan gliserol hasil pemurnian pada konsentrasi asam fosfat $2.5 \%(\mathrm{v} / \mathrm{v}), 5 \%(\mathrm{v} / \mathrm{v})$, dan $7.5 \%(\mathrm{v} / \mathrm{v})$ dapat dilihat pada Tabel 1.

Tabel 1 Hasil sifat fisikokimia gliserol kasar dan gliserol hasil pemurnian pada konsentrasi asam fosfat $2.5 \%, 5 \%$, dan $7.5 \%(\mathrm{v} / \mathrm{v})$

\begin{tabular}{ccccc}
\hline \multirow{2}{*}{ Jenis uji } & \multicolumn{4}{c}{ Sampel } \\
\cline { 2 - 5 } & $\mathrm{K}$ & $\mathrm{M} 1$ & $\mathrm{M} 2$ & $\mathrm{M} 3$ \\
\hline Kadar gliserol (\%) & 53.2930 & 81.5505 & 83.4609 & 80.7595 \\
Bilangan asam (\%) & 1.0036 & 0.7070 & 0.7304 & 0.9002 \\
Kadar air (\%) & 1.7968 & 1.5129 & 1.3717 & 1.5947 \\
Kadar abu (\%) & 5.0243 & 2.2011 & 2.0590 & 1.9818 \\
Densitas (g/cm $\left.{ }^{3}\right)$ & 1.10012 & 1.19633 & 1.21003 & 1.19541 \\
Viskositas (cP) & 270.41 & 20.55 & 22.53 & 18.42 \\
pH & 10 & 4.2 & 3.2 & 2.0 \\
\hline
\end{tabular}

\section{Keterangan:}

$\mathrm{K}$ : Gliserol kasar

M1: Gliserol hasil pemurnian penambahan asam fosfat konsentrasi $2.5 \%$

M2: Gliserol hasil pemurnian penambahan asam fosfat konsentrasi $5 \%$

M3: Gliserol hasil pemurnian penambahan asam fosfat konsentrasi $7.5 \%$ 
Rahmi (2006) melakukan proses pemurnian gliserol dari hasil samping produksi biodiesel minyak inti kelapa sawit melalui metode destilasi sederhana. Metode pemurnian ini berhasil meningkatkan kadar gliserol menjadi $89.24 \%$. Adanya penggunaan panas dari metode destilasi tersebut menyebabkan peningkatan biaya dalam proses pemurnian gliserol yang tidak sebanding dengan nilai ekonomi yang diperoleh. Proses peningkatan kemurnian gliserol yang lebih sederhana dan relatif lebih murah dilakukan oleh Farobie (2009) yaitu dengan menambahkan asam fosfat pada konsentrasi $5 \%(\mathrm{v} / \mathrm{v})$ ke dalam gliserol dari hasil produksi biodiesel tanaman jarak pagar. Asam fosfat ini akan bereaksi dengan sisa katalis kalium hidroksida membentuk garam kalium fosfat yang berwujud padatan. Sisa metanol yang tidak bereaksi dapat dihilangkan dengan memanaskan gliserol pada suhu $65^{\circ} \mathrm{C}$ karena metanol akan menguap pada suhu tersebut. Selain itu asam fosfat akan mengubah sabun dari hasil reaksi antara asam lemak bebas dengan katalis kalium hidroksida pada pembuatan biodiesel menjadi asam lemak bebas. Akibatnya akan terbentuk tiga lapisan yang tidak saling bercampur terdiri dari lapisan atas yaitu asam lemak bebas, lapisan tengah yaitu gliserol, serta lapisan bawah yaitu garam kalium fosfat. Selain menggunakan asam fosfat dengan konsentrasi $5 \%(\mathrm{v} / \mathrm{v})$ dilakukan juga pada konsentrasi asam fosfat $2.5 \%$ dan $7.5 \%(\mathrm{v} / \mathrm{v})$.

Hasil penentuan kadar gliserol menunjukkan sampel gliserol yang masih kasar setelah dilakukan penambahan asam fosfat dengan berbagai konsentrasi telah memenuhi standar SNI yang ada (Tabel 1). Kadar gliserol berdasarkan SNI 06-15641995 minimal 80\%. Hal ini menunjukkan bahwa gliserol hasil pemurnian dapat dimanfaatkan karena kadar gliserol melebihi $80 \%$. Berdasarkan hasil percobaan kadar gliserol murni pada penambahan asam fosfat $5 \%$ lebih tinggi dibandingkan penambahan asam fosfat $7.5 \%$ karena terjadinya proses asidifikasi yang berlebih.

Parameter selanjutnya dilakukan penentuan bilangan asam pada sampel gliserol hasil pemurnian yang telah ditambahkan asam fosfat berbagai konsentrasi. Berdasarkan hasil percobaan bilangan asam pada gliserol hasil pemurnian telah memenuhi standar sesuai literatur (Tabel 1). Menurut Mohtar et al (2001), bilangan asam gliserol dengan kadar $50-80 \%$ sekitar $0.7-1.3 \%$. Kandungan bilangan asam yang rendah tidak akan menimbulkan sifat korosif pada gliserol. Sifat korosif tersebut dapat menurunkan kualitas dari gliserol dalam pemanfaatannya di bidang industri.

Selain bilangan asam dilakukan juga penentuan kadar air pada sampel gliserol hasil pemurnian yang telah ditambahkan asam fosfat berbagai konsentrasi. Berdasarkan hasil percobaan kadar air yang dihasilkan telah memenuhi standar SNI yang ada (Tabel 1). Kadar air yang telah ditetapkan oleh SNI 06-1564-1995 yaitu maksimal 10\%. Namun menurut Mohtar et al (2001), kadar air gliserol hasil pemurnian yang baik sekitar 0.11$0.80 \%$. Hal ini menunjukkan gliserol hasil pemurnian mengandung air yang cukup rendah. Kadar air yang dihasilkan tidak berbanding lurus dengan konsentrasi asam fosfat yang ditambahkan disebabkan adanya proses asidifikasi yang berlebih.

Selanjutnya parameter kadar abu menunjukkan adanya senyawa anorganik berupa logam dan mineral yang terkandung didalamnya. Kadar abu pada sampel gliserol hasil pemurnian yang telah ditambahkan asam fosfat berbagai konsentrasi telah memenuhi standar SNI yang ada (Tabel 1). Kadar abu berdasarkan SNI 06-1564-1995 maksimal $10 \%$. Berdasarkan hasil percobaan kadar abu yang didapat rendah, yang menunjukkan rendahnya senyawa anorganik berupa sisa-sisa logam dan mineral yang terkandung didalamnya.

Penentuan densitas pada sampel gliserol hasil pemurnian yang telah ditambahkan asam fosfat berbagai konsentrasi dilakukan. Hasil penentuan densitas menunjukkan densitas gliserol hasil pemurnian belum memenuhi standar yang ada 
(Tabel 1). Berdasarkan OECD (2002) yang mencantumkan densitas gliserol sebesar $1.261 \mathrm{~g} / \mathrm{cm}^{3}$. Densitas yang didapat belum memenuhi standar sesuai literatur karena dapat dipengaruhi kadar air yang terkandung dalam gliserol hasil pemurnian, semakin tinggi kadar air maka semakin rendah densitasnya.

Hasil penentuan viskositas pada sampel gliserol hasil pemurnian yang telah ditambahkan asam fosfat berbagai konsentrasi menunjukkan nilai viskositas yang dihasilkan belum memenuhi standar yang ada (Tabel 1). Berdasarkan OECD (2002) yang mencantumkan densitas gliserol sebesar $1499 \mathrm{cP}$. Viskositas berbanding lurus dengan densitas (bobot jenis) gliserol, sehingga viskositas gliserol hasil pemurnian belum memenuhi standar yang ada.

Uji pH merupakan faktor penting yang dapat memengaruhi kadar gliserol. Nilai $\mathrm{pH}$ pada sampel gliserol hasil pemurnian yang telah ditambahkan asam fosfat berbagai konsentrasi menunjukkan gliserol paling baik terdapat pada penambahan asam fosfat konsentrasi 5\% (v/v) (Tabel 1). Menurut Rahmi (2006), pH yang paling sesuai untuk proses pemurnian gliserol ialah pada $\mathrm{pH} 3$, karena pada $\mathrm{pH}$ tersebut dapat menghasilkan kadar pemurnian yang terbaik.

\section{SIMPULAN DAN SARAN}

\section{Simpulan}

Berdasarkan hasil analisis terhadap gliserol hasil pemurnian dari hasil samping produksi biodiesel minyak kelapa sawit dapat disimpulkan bahwa pada konsentrasi asam fosfat $5 \% \quad(\mathrm{v} / \mathrm{v})$ diperoleh hasil yang optimal berdasarkan sifat fisikokimianya dibandingkan dengan penambahan asam fosfat konsentrasi $2.5 \%(\mathrm{v} / \mathrm{v})$ dan $7.5 \%(\mathrm{v} / \mathrm{v})$. Kadar pemurnian gliserol dengan hasil optimal tersebut adalah $83 \%$ (sesuai dengan SNI 06-1564-1995).

\section{Saran}

Gliserol yang didapat sebaiknya dimurnikan lagi dengan cara destilasi. Hal ini bertujuan untuk meningkatkan kadar gliserol.

\section{DAFTAR PUSTAKA}

Appleby DB. 2005. Gliserol on The Biodiesel Handbook. Peoria: AOCS Press.

Darnoko D, M Cheryan. 2000. Kinetics of palm oil transesterification in a batch reactor. $J$ Am Oil Chem Soc. 77: 1263-1267.

El-Diwani G, NK Attia, SI Hawash. 2009. Development and evaluation of biodiesel fuel and by-production from jatropha oil. Int J Environ Scien Technol. 6 (2): 219-224.

Farobie O. 2009. Pemanfaatan Gliserol Hasil Samping Produksi Biodiesel sebagai Bahan Penolong Penghancur Semen [Tesis]. Institut Pertanian Bogor. Bogor.

Knohte G. 2005. Dependence of biodiesel fuel properties on structure of fatty acid alkyl esters. Fuel Process Technol. 89: 1059-1070.

Kocsisová T, J Cvengroš. 2006. G-phase from methyl esters production-splitting and refining. Petroleum \& Coal. 48 (2): 1-5.

Mohtar Y, TS Thang, A Salmiah. 2001. Quality of basic oleochemicals produces in Malaysia. Inform. 12 (5): 529-536.

Noureddini H, WR Dailey, BA Hunt. 1998. Production of glycerol ether from crude glycerol the by product of biodiesel production. Papers in Biomaterial. 18: 1-13.

Organization for Economic Cooperation and Development. 2002. CAS 56-81-5: Glycerol. UNEP Publications. Paris. 
Prihandana R, H Roy, N Makmuri. 2006. Menghasilkan Biodiesel Murah. Agromedia Pustaka. Jakarta.

Rahmi U. 2006. Pengaruh Jenis Asam dan pH pada Pemurnian Residu Gliserol dari Hasil Samping Produksi Biodiesel [Skripsi]. Universitas Sumatera Utara. Medan.

Suirta IW. 2009. Preparasi biodiesel dari minyak jelantah kelapa sawit. Jurnal Kimia. 3 (1): $1-6$.

Standar Nasional Indonesia. 1995. SNI 06-1564-1995: Gliserol Kasar. Dewan Standarisasi Nasional. Jakarta. 